\title{
The effects of phylogeny, body size, and locomotor behavior on the three-dimensional shape of the pelvis in extant carnivorans
}

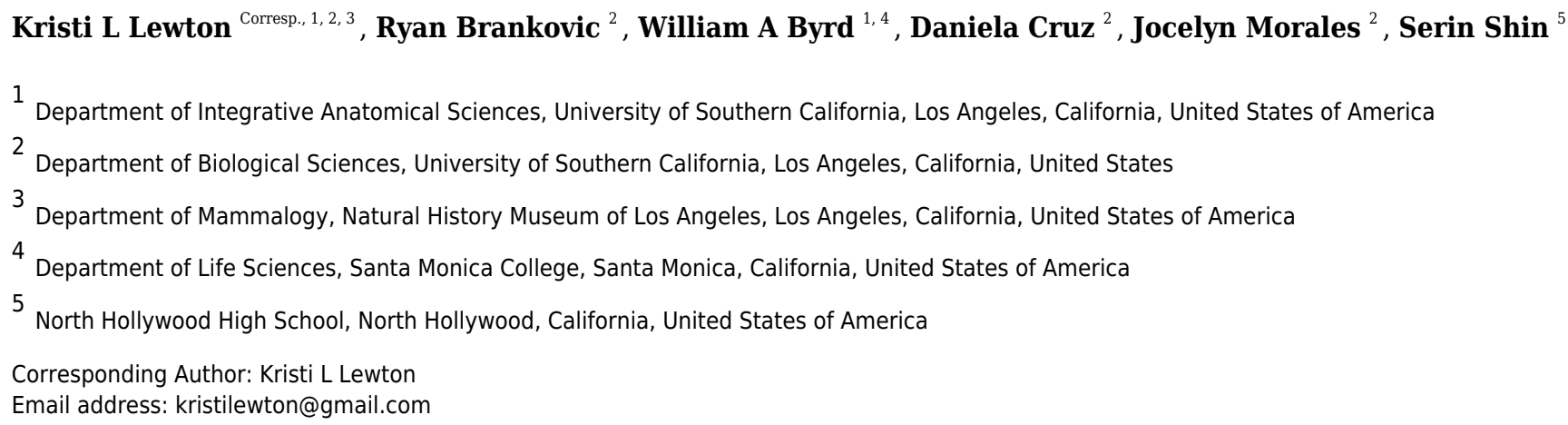

The mammalian pelvis is thought to exhibit adaptations to the functional demands of locomotor behaviors. Previous work in primates has identified form-function relationships between pelvic shape and locomotor behavior; few studies have documented such relationships in carnivorans, instead focusing on long bones. Most work on the functional morphology of the carnivoran pelvis, in particular, has used univariate measures, with only a few previous studies incorporating a three-dimensional (3D) analysis. Here we test the hypothesis that carnivoran taxa that are characterized by different locomotor modes also differ in 3D shape of the os coxae. Using 3D geometric morphometrics and phylogenetic comparative methods, we evaluate the phylogenetic, functional, and size-related effects on 3D pelvis shape in a sample of 33 species of carnivorans. Using surface models derived from laser scans, we collected a suite of landmarks $(\mathrm{N}=24)$ and curve semilandmarks $(\mathrm{N}=147)$. Principal component analysis on Procrustes coordinates demonstrates patterns of shape change in the ischiopubis and ilium likely related to allometry. Phylogenetic generalized least squares analysis on principal component scores demonstrates that phylogeny and body size have greater effects on pelvic shape than locomotor function. Our results corroborate recent research finding little evidence of locomotor adaptation in the pelvis of carnivorans. More research on pelvic morphological integration and evolvability is necessary to understand the factors driving pelvic evolution in carnivorans. 
1 The effects of phylogeny, body size, and locomotor behavior on the three-dimensional

2 shape of the pelvis in extant carnivorans

3

4 5 Serin $\operatorname{Shin}^{5}$

6

8

9

Kristi L. Lewton ${ }^{1,2,3}$, Ryan Brankovic ${ }^{2}$, William A. Byrd ${ }^{1,4}$, Daniela Cruz ${ }^{2}$, Jocelyn Morales ${ }^{2}$,

${ }^{1}$ Department of Integrative Anatomical Sciences, Keck School of Medicine, University of Southern California, Los Angeles, CA USA

${ }^{2}$ Department of Biological Sciences, University of Southern California, Los Angeles, CA, USA

${ }^{3}$ Department of Mammalogy, Natural History Museum of Los Angeles, CA, USA

${ }^{4}$ Department of Life Sciences, Santa Monica College, CA, USA

${ }^{5}$ North Hollywood High School, North Hollywood, CA, USA

Corresponding author information:

Kristi L. Lewton

University of Southern California

Keck School of Medicine

Department of Integrative Anatomical Sciences

1333 San Pablo St., BMT 405

Los Angeles, California 90033-9112

Phone: 323-442-1629

Email: kristilewton@gmail.com

Number of pages: 22

Number of figures: 2

\section{Number of tables: 2}

Running title: 3D pelvic shape in carnivorans

Keywords: 3D geometric morphometrics, pelvis, functional morphology

Grant support: Funding was provided by the University of Southern California. There was no additional external funding received for this study. 


\section{Abstract}

33

34

The mammalian pelvis is thought to exhibit adaptations to the functional demands of locomotor behaviors. Previous work in primates has identified form-function relationships between pelvic shape and locomotor behavior; few studies have documented such relationships in carnivorans, instead focusing on long bones. Most work on the functional morphology of the carnivoran pelvis, in particular, has used univariate measures, with only a few previous studies incorporating a three-dimensional (3D) analysis. Here we test the hypothesis that carnivoran taxa that are characterized by different locomotor modes also differ in 3D shape of the os coxae. Using 3D geometric morphometrics and phylogenetic comparative methods, we evaluate the phylogenetic, functional, and size-related effects on 3D pelvis shape in a sample of 33 species of carnivorans. Using surface models derived from laser scans, we collected a suite of landmarks $(\mathrm{N}=24)$ and curve semilandmarks $(\mathrm{N}=147)$. Principal component analysis on Procrustes coordinates demonstrates patterns of shape change in the ischiopubis and ilium likely related to allometry. Phylogenetic generalized least squares analysis on principal component scores demonstrates that phylogeny and body size have greater effects on pelvic shape than locomotor function. Our results corroborate recent research finding little evidence of locomotor adaptation in the pelvis of carnivorans. More research on pelvic morphological integration and evolvability is necessary to understand the factors driving pelvic evolution in carnivorans. 


\section{Introduction}

Identifying associations between skeletal form and locomotor function are critical for determining how skeletons adapt to the biological roles that they must perform. These formfunction links are especially important for reconstructing locomotor behaviors in extinct species (Rudwick, 1964; Ross et al., 2002). The ossa coxae are a crucial component of the locomotor system because they provide anchorage for the muscles that propel the body during locomotion and they transmit forces from the hindlimb to the torso (Dalstra and Huiskes, 1995). However, the precise relationships between mammalian pelvic form and locomotor function are not well understood because previous studies of mammalian functional morphology have focused primarily on the long bone elements of the fore- and hindlimbs (e.g., Van Valkenburgh, 1987; Schutz and Guralnick, 2007; Lewis and Lague, 2010; Polly, 2010; Fabre et al., 2013; Samuels et al., 2013). Much of the previous work on the mammalian pelvic skeleton in particular has centered on gene expression underlying the embryological development of the mammalian ilium, ischium, and pubis (Pellegrini et al., 2001; Pomikal and Streicher, 2010), and general associations between linear measures of pelvic elements and locomotor behavior or ecomorphology (Davis, 1964; Barry, 1976; Taylor, 1976). Pelvic skeletal functional morphology is more commonly investigated in human and nonhuman primates as a foundation for reconstructing the evolution of bipedality in the hominin lineage and the locomotor behaviors of fossil apes and monkeys (e.g., Berge, 1984; Ward, 1993; Lewton, 2015a, 2015b; Hammond and Almécija, 2017; Ward et al., 2018).

This previous research in primates has demonstrated several key features of the primate pelvis that are adaptations to locomotion (i.e., that differ according to the biomechanical requirements of different locomotor modes), including the dimensions of the iliac blade (e.g., 
74 width, Ward, 1991; Ward et al., 2018), lower ilium (height and cross-sectional area, e.g.,

75 Lewton, 2015a, 2015b; Hammond and Almécija, 2017), ischium (e.g., ischial length, Fleagle and

76

77

78

79

80

81

82

83

84
Anapol, 1992; Lewton and Scott, 2017), and pubis (Lewton, 2015a, 2015b; Lewton and

Dingwall, 2016). This previous research has incorporated both univariate and three-dimensional geometric morphometric data and found the length of the lower ilium to be particularly informative, indicating that larger-bodied primates and/or taxa that encounter relatively large locomotor loads (i.e., large external forces — such as ground reaction forces — that result from locomotor behavior) tend to have shorter, more robust lower ilia presumably to maintain rigidity with increasing mechanical stresses (Lewton, 2015a, 2015b). Relatively short and broad ilia are associated with species that use more orthograde postures and that encounter relatively large locomotor loads, such as bipedal hominins (Le Gros Clark, 1955; Robinson, 1972; Badoux, 1974; Leutenegger, 1974; Lovejoy et al., 2009; Lewton, 2015a, 2015b) and large-bodied vertical clinging and leaping strepsirrhines (Lewton, 2015a, 2015b). Primate ischiopubic morphology is similarly reflective of mechanical needs; species that encounter relatively large locomotor loads have long pubic symphyses and short pubic rami (Howell, 1944; Ward, 1991; Anemone, 1993; Lewton, 2015a, 2015b).

Compared to research on primate pelvic skeletal morphology, less work has been conducted on the functional morphology of the carnivoran pelvis. Previous research on the functional aspects of the carnivoran pelvis has focused primarily on univariate and twodimensional analyses. Early work on carnivoran pelvic morphology in relationship to locomotor function yielded mixed results; differences among locomotor groups in pelvic morphology were identified (Davis, 1964; Barry, 1976; Taylor, 1976), but the functional relevance of these differences was not well understood (Davis, 1964). Combining kinematic (from cineradiographs)

Peer] reviewing PDF | (2019:10:42665:1:0:NEW 12 Jan 2020) 
97 and limited morphological data (acetabular coverage of the femoral head) from procyonids,

98 felids, and canids, Jenkins and Camazine (1977) found functional relationships between the

99 position and angular excursion of the femur during locomotion with articular morphologies of

100 the femoral head; for example, cursorial carnivorans exhibit morphologies that restrict hip

101 abduction capabilities to maintain limb movements in a parasagittal plane. More recently,

102 Martín-Serra and colleagues (2014a) used 3D geometric morphometric methods to investigate

103 the effects of locomotion on pelvic morphology. Using 16 landmarks on the ilium, ischium, and

104 pubis, Martín-Serra et al. (2014a) found significant effects of phylogeny and body size on pelvic

105 morphology, but the effect of locomotor behavior was less clear as locomotor behaviors were

106 correlated with phylogeny. However, Martín-Serra and colleagues (2014a) captured some, but

107 not all, aspects of pelvic shape, as their study did not use semilandmarks and, as a result, did not

108 record the shape of the prominent curves of the pelvis such as the iliac crest, the arcuate line, or

109 the shape of the ischiopubis, and they did not include representatives of herpestids, mephitids, or

110 viverrids. These data would be informative because they provide information related to the shape

111 of prominent regions of attachment for muscles that are involved in propulsion of the hindlimb

112 and in flexion and extension of the spine (e.g., the hindlimb extensors along the ilium and

113 ischium and the erector spinae muscles along the medial aspect of the iliac crest, respectively).

114 These bony regions have been shown in other mammals to correlate with locomotor behavior

115 and adaptation (e.g., Lewton, 2015b; Ward et al., 2018). Furthermore, the inclusion of species of

116 herpestids, mephitids, and viverrids is important because it allows an investigation of the effects

117 of body size on pelvic shape by including more carnivoran taxa that are small-bodied, and it also

118 expands the locomotor and postural behaviors in the sample (e.g., including semifossorial 
119 species). Therefore, the aim of this paper is to test functional hypotheses of pelvic form in the

120 Order Carnivora using a phylogenetically-diverse sample and 3D shape data.

121

122 Methods

123

The osteological sample comprises ossa coxae of 56 specimens of 33 species from 10

124 families of Carnivora from the Department of Mammalogy at the Natural History Museum of

125 Los Angeles (Table 1). To increase sample sizes per taxon, we included both captive and wild

126 specimens and used a mixed-sex sample (see Supplemental Information). The locomotor

127 behavior of each taxon was categorized into six locomotor groups (arboreal, cursorial, natatorial,

128 scansorial, semifossorial, or terrestrial). Locomotor behavior classifications were derived from

129 the literature (see references in Table 1). Data were collected on the right os coxae of adult

130 specimens (judged by pelvic epiphyseal fusion).

131 Three-dimensional os coxae models were constructed from laser scans using a

132 NextEngine HD Laser Scanner (NextEngine, Inc., Santa Monica). Scan settings varied

133 depending on the size of the specimen, where small specimens were scanned in macro mode, and 134 larger specimens in wide mode. High definition (HD) settings and 12-13 rotations were used for

135 all scans. Specimens were scanned in two to three orientations to ensure adequate capture of the

136 entire surface. Scans were exported as polygon (.ply) files and were digitally aligned and merged

137 in Geomagic Wrap software (3D Systems, Inc., Morrisville, NC). Surface models were then

138 processed in Geomagic, which included removing spikes and filling small holes in the mesh. The

139 resulting .ply files were imported into Checkpoint software (Stratovan Corp., Davis) and a suite

140 of 3D landmarks $(\mathrm{N}=24)$ and semilandmarks $(\mathrm{N}=147)$ were digitally extracted from each model

141 (Fig. 1, Table 2; the raw, unadjusted landmarks for all specimens are provided in the 
142 Supplemental Information). Landmarks reflect homologous anatomical locations based on

143 muscle attachments, joint articulations, loci of epiphyseal fusion, or other regions of anatomical

144 interest following Lewton $(2012,2015 b)$. Semilandmarks were placed along the following eight

145 curves: 1) iliac crest, 2) arcuate line, 3) dorsal iliac margin, 4) acetabular lunate surface rim -

146 external margin, 5) acetabular lunate surface rim - internal margin, 6) ischiopubic ramus margin,

147 7) lateral iliac margin, 8) obturator foramen margin (Fig. 1). One specimen (LACM 90728) had a

148 small hole in the acetabular notch that precluded placement of Landmark 11, so this landmark

149 was estimated using the estimate.missing function in the 'geomorph' package (Adams et al.,

150 2019) for R software (R Core Team, 2019).

All landmarks were placed on surface models by a single observer (WAB). Intraobserver

152 landmark error was assessed by repeating the landmarking process five times on a single

153 specimen and calculating the percent error for each landmark. The average error over all

154 landmarks was 1.98\%. Only one landmark had an error rate over 5\% (Landmark 11, the center of 155 the acetabulum, 7\% error).

156 Geometric morphometric methods were used to test hypotheses of shape differences

157 among locomotor groups. Landmark configurations were scaled, rotated, and translated using

158 Generalized Procrustes Analysis. The criterion used for sliding semilandmarks along curves was

159 minimizing bending energy (Gunz and Mitteroecker, 2013). Species means of Procrustes

160 coordinates were computed and principal component analysis (PCA) was performed using a

161 phylomorphospace approach.

162

All phylogenetic comparative analyses used a tree derived from Nyakatura and Bininda-

163 Emonds's (2012) Carnivora supertree based on molecular data (available in the Supplemental

164 Information). The treedata function in the 'geiger' package (Harmon et al., 2008) for R software 
165 (R Core Team, 2019) was used to ensure that the species mean principal component (PC) scores 166 and the tree topology were concordant. The effects of locomotor behavior and body size on

167 pelvic shape were tested using phylogenetic generalized least squares analysis (PGLS). Because 168 pelvis size correlates with body size (e.g., Ward, 1991; Lewton, 2010; Lewton, 2015a; Ward et 169 al., 2018), centroid size of the landmark configuration was used as an estimate of overall body 170 size. The PGLS regressions take the form of PC score $\sim$ locomotion + centroid size, where 171 "locomotion" is a categorical variable with six levels. Degree of phylogenetic signal in the 172 Procrustes coordinates was assessed using the multivariate K-statistic (Adams, 2014). All 173 geometric morphometric analyses were conducted using the 'geomorph' (Adams et al., 2019) 174 package for R software (see Supplemental Information for R code and files).

Results

Principal component analysis and phylomorphospace

The first four principal components (PCs) describe $74 \%$ of the variation in this sample. PC 1 reflects variation in ischiopubic shape and describes $31 \%$ of sample variation. PC 2 relates to ilium width and orientation and describes $23 \%$ of sample variation. Figure 2 a plots PC 2 on PC 1 and shows some separation in phylomorphospace among taxonomic groups. Along PC 1, 182 species with more negative PC 1 scores demonstrate triangular pubic bones, with longer pubic 183 rami and shorter pubic symphyses; taxa that exemplify more triangular pubic bones are skunks.

184 Other taxa with negative PC 1 scores include ursids, civets, raccoons, aardwolves, and some 185 herpestids. Species with more positive PC scores demonstrate square-shaped pubic bones, with shorter iliopubic and ischiopubic rami and longer pubic symphyses; taxa that exemplify more square-shaped pubic bones are felids and canids. Along PC 2, species with more negative PC 
188 scores (e.g., ursids, aardwolves, raccoons, and coyotes) exhibit wider and more laterally-flaring

189 iliac blades, while species with more positive PC 2 scores (e.g., civets and most herpestids)

190 exhibit narrow ilia with the iliac blade oriented in a parasagittal plane.

191 Variation in phylomorphospace among taxa in the PC 3 vs PC 4 plot generally

192 corresponds to family; shape variation along these axes is minimal (Figure 2b). PC 3 reflects

193 variation in overall length of the ilium and ischium and describes $13.5 \%$ of sample variation.

194 Canids generally have positive PC3 scores (reflecting shorter ischia and longer ilia), while felids

195 and herpestids generally have negative PC3 scores (reflecting longer ischia and shorter ilia). PC

1964 reflects variation in ilium width and orientation and ischium breadth and describes $6.5 \%$ of

197 sample variation. Palm civets are separated from all other taxa at the positive end of PC 4,

198 reflecting wide ilia that are slightly more parasagittally-aligned, and broader ischia. Other taxa

199 with positive PC 4 scores include most of the felids and canids (but notably not the most

200 terrestrial felids, the manul, serval, and cheetah). Taxa with negative PC 4 scores (reflecting

201 narrower ilia and more slender ischia) include herpestids, skunks, and the most terrestrial felids.

202

203

Phylogenetic generalized least squares analysis

204

The degree of phylogenetic signal in the species-mean Procrustes shape variables is

205

206

207

208

209

210 statistically significant $(\mathrm{K}=0.52, \mathrm{p}=0.001)$. The PGLS analysis demonstrated that neither

locomotor mode nor size had a significant effect on $\mathrm{PC} 1(\mathrm{~F}=0.72, \mathrm{p}=0.60$ and $\mathrm{F}=1.41, \mathrm{p}=0.25$,

respectively) and that locomotor mode did not have a significant effect on PC 2 and PC 3

$(\mathrm{F}=2.37, \mathrm{p}=0.07$ and $\mathrm{F}=1.32, \mathrm{p}=0.28$, respectively). Size, however, did have a significant effect

on PC 2 and $\mathrm{PC} 3(\mathrm{~F}=30.3, \mathrm{p}=0.0001$ and $\mathrm{F}=6.53, \mathrm{p}=0.02$, respectively). For PC 4 , the PGLS

model demonstrated that neither locomotor mode nor size were significant $(F=2.35, p=0.08$ and 
$211 \mathrm{~F}=1.36, \mathrm{p}=0.26$, respectively). The correlation between PC 2 and log-centroid size is negative ( $\mathrm{r}$

$212=-0.67)$, indicating that taxa located at the negative end of the PC 2 axis are larger than those at

213 the positive end (Fig. 2a). Although the correlation between PC 3 and log-centroid size is

214 statistically significant $(\mathrm{r}=0.41)$, a bivariate plot indicates no relationship between these two

215 variables.

216

217 Discussion

We tested the hypothesis that carnivorans that differ in habitual locomotor behavior

219

220

221

222

223

224

225

226

227

228

229

230

231

232

233

would exhibit significantly different 3D pelvic shapes. This hypothesis was not supported.

Although carnivorans demonstrate variation in pelvic shapes, the primary factors influencing shape are phylogeny and size, not locomotor function. These results are somewhat surprising given documented differences in pelvic morphology due to locomotion and positional behavior in other mammals (Ward, 1991; Anemone, 1993; Álvarez et al., 2013; Lewton, 2015a, 2015b; Lewton and Dingwall, 2016; Tague, 2019).

Previous research on carnivoran pelvic shape has primarily focused on two-dimensional (2D) geometric morphometrics (Álvarez et al., 2013) and univariate analyses of linear measures (Davis, 1964; Barry, 1976; Taylor, 1976). Using 2D pelvic landmarks on a sample of nine orders of mammals, Álvarez et al. (2013) documented variation in acetabulum size, ventral elongation of the pubis, the length of the pubic symphysis, and dorsal projection of the ischial tuberosity. Variation in ilium morphology was not fully captured by this previous work because only two landmarks were placed on the ilium (Álvarez et al., 2013). As in our study, significant phylogenetic signal was found in 2D pelvis shape (Álvarez et al., 2013), although these authors also suggested that variation in pelvic shape was related to speed of locomotion, with high-speed 
234 taxa demonstrating a long ischium and pubic symphysis. Similarly, Barry's (1976) analysis of

235 univariate pelvic dimensions demonstrated speed-related morphological variation, with

236 separation between cursorial and ambulatory taxa.

237 In a recent study using 3D geometric morphometric methods on pelvic bones, Martín-

238 Serra et al. (2014a) found that phylogeny and body size have greater effects on pelvic shape than

239 locomotor behavior. Our study expanded upon Martín-Serra and colleagues' by sampling from

240 additional carnivoran families, incorporating more landmarks, and including semilandmarks to

241 capture pelvic curves. It is important to note, however, that Martín-Serra et al.'s (2014a) sample

242 was larger and included more taxonomic and behavioral diversity within some families (canids,

243 hyaenids, mustelids, and ursids) than the present sample. Our results corroborate those of

244 Martín-Serra and colleagues: within carnivorans, pelvis anatomy is more closely related to

245 phylogeny and body size than to locomotor behavior. Parallel analyses on the carnivoran

246 forelimb by Martín-Serra et al. (2014b) also find that morphological differences are driven by

247 phylogenetic constraint and body size and not locomotor behavior.

248 Nevertheless, shape variation in our principal component analyses shows some of the

249 same morphological patterns, particularly in the pubis and ilium, as previous work in primates

250 (Lewton, 2015b). In strepsirrhines, scores along the first principal component also describe a

251 spectrum in pubic bone morphology from square to triangular, in which square pubic bones have

252 relatively short pubic rami and long pubic symphyses, and triangular pubic bones have relatively

253 long pubic rami and short symphyses (Lewton, 2015b). In primates, these differences in the

254 shape of the pubic bones were related to differences in body size and potentially locomotor load

255 magnitudes, in which small-bodied primates exhibited elongation of the pubic bones and large-

256 bodied primates exhibited short and broad pubic bones. Variation along the second principal 
257 component in primates related to differences in arboreal versus leaping behaviors, in which

258 arboreal primates exhibited small acetabulae and long ischia and pubic symphyses, while leaping

259 primates exhibited the opposite pattern (Lewton, 2015b).

260 Similarly, the variation in ilium width demonstrated here echoes patterns exhibited in

261 primates. Across primates, ilium width scales with positive allometry (Lewton, 2015a; Middleton

262 et al., 2017; Ward et al., 2018), and large-bodied orthograde species (such as indriids and

263 hominoids) exhibit wider ilia than expected (Lewton, 2015a,b). A comparison of locomotor

264 groups within strepsirrhines shows that large-bodied vertical clingers and leapers have relatively

265 wider ilia than their small-bodied counterparts and arboreal quadrupedal sister taxa (Lewton,

266 2015b). In the present study, the widest ilia belong to ursids, a finding noted by other researchers

267 (e.g., Davis, 1964; Martín-Serra et al., 2015) and attributed to "peculiarities, still unknown, in the

268 abdominal wall muscles" (Davis, 1964, p. 110). Given that ursids are some of the largest taxa in

269 this sample, their wide ilia lend further support to the previous findings of positive allometry in

270 ilium width in primates. Although ursids do not habitually use orthograde postures, they are

271 capable of assuming orthograde postures (Davis, 1964) and their pelvic shape may be indicative

272 of the ability to accommodate facultative orthogrady (see also Russo and Williams, 2015).

273 Nevertheless, the functional relevance of wide ilia to orthogrady is not widely supported within

274 our sample of carnivorans.

275 Our finding of a lack of locomotor effect on pelvic morphology could result from

276 possible limitations of our study. We aimed to increase taxonomic sampling and thus include a

277 mixed-sex sample of a large number of taxa, but relatively small samples per taxon. In addition,

278 we used both captive- and wild-reared animals in an effort to increase sample sizes. Although

279 some differences in long bone articular surface areas have been found in the proximal tibial and 
280 distal ulnar joint surfaces between captive- versus wild-reared chimpanzee individuals (Lewton,

281 2017), consistent differences in postcranial morphology between captive and wild specimens are

282 not documented (Bello-Hellegouarch et al., 2013; Turner et al., 2016). Previous work has not

283 identified broad patterns of sexual dimorphism in pelvic shape or size across carnivorans,

284 although Schutz et al. (2009) found that pelvic shape and size is dimorphic in the small-bodied

285 island fox, Urocyon littoralis. Although an examination of intraspecific pelvic variation is

286 beyond the scope of this study, future work could investigate the effects of sex and rearing on the

287 shape of the carnivoran pelvis.

288 Given recent work demonstrating a lack of locomotor adaptive signal in the 3D

289 morphology of the carnivoran pelvic girdle, future research that delves into patterns of limb

290 girdle modularity, evolvability, and constraint is needed to determine whether evolutionary

291 constraint limits pelvis evolutionary flexibility (e.g., Marroig et al., 2009) to adapt to different

292 locomotor regimes. It has been suggested that the carnivoran pelvis is modular, with the ilium,

293 ischium, pubis, and acetabulum representing four modules, and that carnivoran families differ in

294 their patterns of pelvic modularity (Martín-Serra et al., 2018). However, patterns of

295 morphological integration of pelvic features and estimates of evolvability of pelvic shape have

296 not been investigated in carnivorans. Recent work on patterns of morphological integration

297 between and within limbs in carnivoran demonstrates that cursors have higher levels of

298 morphological integration than non-cursors (Martín-Serra et al., 2015), suggesting that having

299 other functional roles of the forelimb beyond terrestrial locomotion has resulted in increased

300 responsiveness to functional selection pressures in non-cursor carnivorans. Therefore, lack of

301 pelvic variation in carnivoran cursors may be related to increased levels of limb integration.

302 Alternatively, one might hypothesize that proximal limb elements are less responsive to 
303 locomotor selection pressures than distal limb elements, which likely encounter larger forces due 304 to their proximity to the substrate. However, this is not the case in other mammalian orders. For 305 example, in Primates, the pelvis exhibits low levels of integration, high levels of modularity 306 (Grabowski et al., 2011; Lewton, 2012), and differences in shape that correlate with locomotor 307 mode (e.g., Lewton, 2015a,b; Ward et al., 2018). One way to address this question would be to 308 examine adaptation, integration, and modularity within and among multiple hindlimb elements to 309 discern whether there are proximal-to-distal patterns. These data will be critical to developing an 310 explanation of the drivers of pelvic evolution within Carnivora.

\section{Conclusions}

We tested the hypothesis that carnivoran species differ in 3D shape of the pelvic bones according to locomotor function. In a taxonomically diverse sample of carnivorans, we used 3D geometric morphometrics and phylogenetic comparative methods to assess the phylogenetic, functional, and size-related effects on 3D pelvis shape. Our analyses revealed differences among taxa in pelvic shape related to size and phylogeny, but not locomotor function. These findings are similar to those of previous researchers who have found that 3D shape of the appendicular skeleton does not exhibit clear relationships with locomotor function (Martín-Serra et al., 2014a,b). Our study highlights the effects of body size and allometric requirements on skeletal

321 biology and draws parallels with previous research on pelvic bone allometry and locomotor 322 function in the Order Primates. 
Angeles for specimen access.

\section{References}

329

Adams DC. 2014. A generalized K statistic for estimating phylogenetic signal from shape and other high-dimensional multivariate data. Syst Biol 63:685-697.

Adams DC, Collyer ML, Kaliontzopoulou A. 2019. Geomorph: software for geometric morphometric analyses.

Álvarez A, Ercoli MD, Prevosti FJ. 2013. Locomotion in some small to medium-sized mammals: a geometric morphometric analysis of the penultimate lumbar vertebra, pelvis and hindlimbs. Zoology 116:356-371.

Anemone RL. 1993. The functional anatomy of the hip and thigh in primates. In: Gebo DL, editor. Postcranial adaptation in nonhuman primates. p. 150-174.

Badoux DM. 1974. An introduction to biomechanical principles in primate locomotion and posture. In: Jenkins FA Jr, editor. Primate locomotion. New York: Academic Press. p. 143.

Barry JC. 1976. The pelvic anatomy and adaptations of extant fissiped carnivores [Doctoral dissertation]. Yale University.

Bekoff M. 1977. Canis latrans. Mammalian Species 79:1-9.

Bello-Hellegouarch G, Potau JM, Arias-Martorell J, Pastor JF, Pérez-Pérez A. 2013. Brief communication: Morphological effects of captivity: A geometric morphometric analysis of the dorsal side of the scapula in captive-bred and wild-caught Hominoidea. Am J Phys Anthropol 152:306-310. 
348 Berge C. 1984. Multivariate analysis of the pelvis for hominids and other extant primates: implications for the locomotion and systematics of the different species of australopithecines. J Hum Evol 13:555-562.

Dalstra M, Huiskes R. 1995. Load transfer across the pelvic bone. J Biomech 28:715-724.

Davis DD. 1964. The giant panda: a morphological study of evolutionary mechanisms. Chicago: Chicago Natural History Museum.

Fabre AC, Cornette R, Slater G, Argot C, Peigné S, Goswami A, Pouydebat E. 2013. Getting a grip on the evolution of grasping in musteloid carnivorans: a three-dimensional analysis of forelimb shape. J Evol Biol 26:1521-1535.

Fleagle JG, Anapol FC. 1992. The indriid ischium and the hominid hip. J Hum Evol 22:285-305.

Grabowski MW, Polk JD, Roseman CC. 2011. Divergent patterns of integration and reduced constraint in the human hip and the origins of bipedalism. Evolution 65:1336-1356.

Gunz P, Mitteroecker P. 2013. Semilandmarks: a method for quantifying curves and surfaces. Hystrix, the Italian Journal of Mammalogy 24:103-109.

Hammond AS, Almécija S. 2017. Lower ilium evolution in apes and hominins. Anat Rec 300:828-844.

Harmon LJ, Weir JT, Brock CD, Glor RE, Challenger W. 2008. GEIGER: investigating evolutionary radiations. Bioinformatics 24:129-131.

Howell AB. 1944. Speed in animals: their specialization for running and leaping. Chicago: University of Chicago Press.

Jenkins FA, Camazine SM. 1977. Hip structure and locomotion in ambulatory and cursorial carnivores. J Zool 181:351-370.

Koehler CE, Richardson PRK. 1990. Proteles cristatus. Mammalian Species 363:1-6. 
371 Le Gros Clark WE. 1955. The os innominatum of the recent Ponginae with special reference to

372

373

374

375

376

377

378

379

380

381

382

383

384

385

386

387

388

389

390

391

392

393 that of the Australopithecinae. Am J Phys Anthropol 13:19-27.

Leutenegger W. 1974. Functional aspects of pelvic morphology in simian primates. J Hum Evol $3: 207-222$.

Lewis ME, Lague MR. 2010. Interpreting sabretooth cat (Carnivora; Felidae; Machairodontinae) postcranial morphology in light of scaling patterns in felids. In: Goswami A, Friscia A, editors. Carnivoran evolution: new views on phylogeny, form, and function. Cambridge: Cambridge University Press. p. 411-465.

Lewton KL. 2010. Locomotor function and the evolution of the primate pelvis [PhD dissertation]. Arizona State University.

Lewton KL. 2012. Evolvability of the primate pelvic girdle. Evol Biol 39:126-139.

Lewton KL. 2015a. Allometric scaling and locomotor function in the primate pelvis. Am J Phys Anthropol 156:511-530.

Lewton KL. 2015b. Pelvic form and locomotor adaptation in strepsirrhine primates. Anat Rec 298:230-248.

Lewton KL. 2017. The effects of captive versus wild rearing environments on long bone articular surfaces in common chimpanzees (Pan troglodytes). PeerJ 5:e3668.

Lewton KL, Dingwall HL. 2016. Morphological convergence in the pubis of slow-moving primates and xenarthrans. Am J Phys Anthropol 161:381-397.

Lewton KL, Scott JE. 2017. Ischial form as an indicator of bipedal kinematics in early hominins: A test using extant anthropoids. Anat Rec 300:845-858.

Lovejoy CO, Suwa G, Spurlock L, Asfaw B, White TD. 2009. The pelvis and femur of Ardipithecus ramidus: the emergence of upright walking. Science 326:71e1-6. 
394 Marroig, G., Shirai, L. T., Porto, A., de Oliveira, F. B., \& De Conto, V. 2009. The evolution of 395 modularity in the mammalian skull II: Evolutionary consequences. Evol Biol, 36, 136-

396

397

398

399

400

401

402

403

404

405

406

407

408

409

410

411

412

413

414

415 148.

Martín-Serra A, Figueirido B, Palmqvist P. 2014a. A three-dimensional analysis of the morphological evolution and locomotor behaviour of the carnivoran hind limb. BMC Evol Biol 14:129.

Martín-Serra A, Figueirido B, Palmqvist P. 2014b. A three-dimensional analysis of morphological evolution and locomotor performance of the carnivoran forelimb. PLoS One 9:e85574.

Martín-Serra A, Figueirido B, Pérez-Claros JA, Palmqvist P. 2015. Patterns of morphological integration in the appendicular skeleton of mammalian carnivores. Evolution 69:321-340.

Martín-Serra A, Figueirido B, Palmqvist P. 2018. Changing modular patterns in the carnivoran pelvic girdle. J Mammal Evol. https://doi.org/10.1007/s10914-018-9454-9.

Meachen-Samuels J, Van Valkenburgh B. 2009. Forelimb indicators of prey-size preference in the Felidae. J Morphol 270(6):729-44.

Middleton ER, Winkler ZJ, Hammond AS, Plavcan JM, Ward CV. 2017. Determinants of iliac blade orientation in anthropoid primates. Anat Rec 300:810-827.

Moore CM, Collins PW. 1995. Urocyon littoralis. Mammalian Species 489:1-7.

Morlo M, Gunnell GF, Nagel D. 2010. Ecomorphological analysis of carnivore guilds in the Eocene through Miocene of Laurasia. In: Goswami A, Friscia A, editors. Carnivoran evolution: new views on phylogeny, form, and function. Cambridge: Cambridge University Press. p. 269-310. 
416 Nowak, RM. 2005. Walker's Carnivores of the World. Baltimore: The Johns Hopkins University 417 Press.

418 Nyakatura K, Bininda-Emonds ORP. 2012. Updating the evolutionary history of Carnivora

419 (Mammalia): a new species-level supertree complete with divergence time estimates.

420 BMC Biol 10:12.

421

422

423

424

425

426

427

428

429

430

431

432

433

434

435

436

437

438

Pellegrini M, Pantano S, Fumi MP, Lucchini F, Forabosco A. 2001. Agenesis of the scapula in Emx2 homozygous mutants. Dev Biol 232:149-156.

Polly PD. 2010. Tiptoeing through the trophics: geographic variation in carnivoran locomotor ecomorphology in relation to environment. In: Goswami A, Friscia A, editors. Carnivoran evolution: new views on phylogeny, form, and function. Cambridge: Cambridge University Press. p. 374-410.

Pomikal C, Streicher J. 2010. 4D-analysis of early pelvic girdle development in the mouse (Mus musculus). J Morphol 271:116-126.

Presley SJ. 2000. Eira barbara. Mammalian Species 636:1-6.

R Core Team. 2019. R: A language and environment for statistical computing. R Foundation for Statistical Computing, Vienna, Austria. https://www.R-project.org/.

Roberts MS, Gittleman JL. 1984. Ailurus fulgens. Mammalian Species 222:1-8.

Robinson JT. 1972. Early hominid posture and locomotion. Chicago: University of Chicago Press.

Ross CF, Lockwood CA, Fleagle JG, Jungers WL. 2002. Adaptation and behavior in the primate fossil record. In: Plavcan JM, Kay RF, Jungers WL, van Schaik CP, editors. Reconstructing behavior in the primate fossil record. New York: Kluwer Academic/Plenum Publishers. p. 1-41. 
439 Rudwick MJS. 1964. The inference of function from structure in fossils. Br J Philos Sci 15:27-

440

441

442

443

444

445

446

447

448

449

450

451

452

453

454

455

456

457

458

459

460

461

40.

Russo GA, Williams SA. 2015. Giant pandas (Carnivora: Ailuropoda melanoleuca) and living hominoids converge on lumbar vertebral adaptations to orthograde trunk posture. J Hum Evol 88:160-179.

Samuels JX, Meachen JA, Sakai SA. 2013. Postcranial morphology and the locomotor habits of living and extinct carnivorans. J Morphol 274:121-146.

Schutz H, Guralnick RP. 2007. Postcranial element shape and function: assessing locomotor mode in extant and extinct mustelid carnivorans. Zool J Linn Soc 150:895-914.

Schutz H, Polly PD, Krieger JD, Guralnick RP. Differential sexual dimorphism: size and shape in the cranium and pelvis of grey foxes (Urocyon). Biol J Linn Soc 96:339353. https://doi.org/10.1111/j.1095-8312.2008.01132.x

Sunquist M, Sunquist F. 2002. Wild Cats of the World. Chicago: The University of Chicago Press.

Tague RG. 2005. Big-bodied males help us recognize that females have big pelves. Am J Phys Anthropol 127(4):392-405.

Tague RG. 2019. Commonality in pelvic anatomy among three fossorial, scratch-digging, mammalian species. J Mammal Evol 1-13.

Taylor ME. 1976. The functional anatomy of the hindlimb of some African Viverridae (Carnivora). J Morphol 148:227-254.

Taylor PJ, Meester J. 1993. Cynictis penicillate. Mammalian Species 432:1-7.

Trapp GR, Hallberg DL. 1975. Ecology of the gray fox (Urocyon cinereoargenteus): a review. The wild canids. New York: Van Nostrand-Reinhold, New York. p. 164-178. 
462 Turner TR, Cramer JD, Nisbett A, Patrick Gray J. 2016. A comparison of adult body size

463

464

465

466

467

468

469

470

471

472

473

474

475

476

477

478

479

480

481

482

483

484 between captive and wild vervet monkeys (Chlorocebus aethiops sabaeus) on the island of St. Kitts. Primates 57:211-220.

Van Valkenburgh B. 1987. Skeletal indicators of locomotor behavior in living and extinct carnivores. J Vertebr Paleontol 7:162-182.

Wade-Smith J, Verts BJ. 1982. Mephitis mephitis. Mammalian Species 173:1-7.

Ward CV. 1991. Functional anatomy of the lower back and pelvis of the Miocene hominoid Proconsol nyanzae from Mfangano Island, Kenya [PhD dissertation]. The Johns Hopkins University.

Ward CV. 1993. Torso morphology and locomotion in Proconsul nyanzae. Am J Phys Anthropol 92:291-328.

Ward CV, Maddux SD, Middleton ER. 2018. Three-dimensional anatomy of the anthropoid bony pelvis. Am J Phys Anthropol 166:3-25.

Ward OG, Wurster-Hill DH. 1990. Nyctereutes procyonoides. Mammalian Species 358:1-5.

Wilson AM, Lowe JC, Roskilly K, Hudson PE, Golabek KA, McNutt JW. 2013. Locomotion dynamics of hunting in wild cheetahs. Nature 498(7453):185.

\section{Figure Legends}

Figure 1. Three-dimensional landmarks are shown in ventral (A), lateral (B), and dorsal (C) views on a fox (Vulpes Vulpes) os coxae. Yellow labeled points indicate landmarks, while black points and lines indicate semilandmark curves. Landmark and curve definitions are listed in Table 2. 
485 Figure 2. Phylomorphospace plots for PC1 on PC2 (A) and PC3 on PC4 (B). The phylogeny is 486 shown in grey, points correspond to species means PC scores, colored by locomotor category.

487 Legend in (B) follows (A). The os coxae shapes represented by the extremes of the PC axes are 488 shown on the right.

489 


\section{Table $\mathbf{1}$ (on next page)}

Sample size and locomotor category for each taxon $(\mathrm{N}=33)$. 
Table 1. Sample size and locomotor category for each taxon ( $N=33$ ).

Locomotio

\begin{tabular}{|c|c|c|c|}
\hline Taxon & $\mathbf{N}$ & $\mathbf{n}$ & Behavioral reference \\
\hline \multicolumn{4}{|l|}{ Ailuridae } \\
\hline Ailurus fulgens & 2 & arboreal & Nowak (2005); Roberts \& Gittleman (1984) \\
\hline \multicolumn{4}{|l|}{ Canidae } \\
\hline Canis latrans & 2 & cursorial & Bekoff (1977) \\
\hline Nyctereutes & & & \\
\hline procyonoides & 1 & terrestrial & Ward \& Wurster-Hill (1990) \\
\hline Otocyon megalotis & 2 & cursorial & Morlo et al. (2010) \\
\hline \multicolumn{4}{|c|}{ Urocyon } \\
\hline cinereoargenteus & 2 & scansorial & Trapp \& Hallberg (1975) \\
\hline Urocyon littoralis & 5 & terrestrial & Moore \& Collins (1995) \\
\hline Vulpes vulpes & 2 & cursorial & Nowak (2005) \\
\hline \multicolumn{4}{|l|}{ Felidae } \\
\hline Acinonyx jubatus & 1 & cursorial & Sunquist \& Sunquist (2002); Wilson et al. (2013) \\
\hline & & & Meachen-Samuels \& Van Valkenburgh (2009); Sunquist \& Sunquist \\
\hline Felis silvestris & 1 & scansorial & $(2002)$ \\
\hline & & & Meachen-Samuels \& Van Valkenburgh (2009); Sunquist \& Sunquist \\
\hline Leptailurus serval & 1 & terrestrial & $(2002)$ \\
\hline Lynx canadensis & 2 & scansorial & Van Valkenburgh (1987) \\
\hline & & & Meachen-Samuels \& Van Valkenburgh (2009); Sunquist \& Sunquist \\
\hline Lynx rufus & 3 & scansorial & $(2002)$ \\
\hline & & & Meachen-Samuels \& Van Valkenburgh (2009); Sunquist \& Sunquist \\
\hline Otocolobus manul & 1 & terrestrial & $(2002)$ \\
\hline & & & Meachen-Samuels \& Van Valkenburgh (2009); Sunquist \& Sunquist \\
\hline Panthera leo & 1 & terrestrial & $(2002)$ \\
\hline Panthera pardus & 1 & scansorial & Sunquist \& Sunquist (2002); Van Valkenburgh (1987) \\
\hline & & & Meachen-Samuels \& Van Valkenburgh (2009); Sunquist \& Sunquist \\
\hline Panthera tigris & 2 & terrestrial & $(2002)$ \\
\hline $\begin{array}{l}\text { Prionailurus } \\
\text { benaalensis }\end{array}$ & 1 & scansorial & $\begin{array}{l}\text { Meachen-Samuels \& Van Valkenburgh (2009); Sunquist \& Sunquist } \\
\text { (2002) }\end{array}$ \\
\hline Puma concolor & 2 & scansorial & Sunquist \& Sunquist (2002); Van Valkenburgh (1987) \\
\hline \multicolumn{4}{|l|}{ Herpestidae } \\
\hline Atilax paludinosus & 2 & $\begin{array}{l}\text { natatorial } \\
\text { semifossori }\end{array}$ & Baker (1992); Nowak (2005) \\
\hline Cynictis penicillata & 2 & al & Taylor \& Meester (1993) \\
\hline Galerella pulverulenta & 1 & terrestrial & Nowak (2005) \\
\hline Galerella sanguinea & 1 & terrestrial & Nowak (2005); Taylor (1976) \\
\hline Herpestes ichneumon & 1 & terrestrial & Nowak (2005); Taylor (1976) \\
\hline Mungos mungo & 1 & terrestrial & Nowak (2005); Taylor (1976) \\
\hline \multicolumn{4}{|l|}{ Hyaenidae } \\
\hline Proteles cristata & 3 & terrestrial & Koehler \& Richardson (1990) \\
\hline \multicolumn{4}{|l|}{ Mephitidae } \\
\hline & & semifossori & \\
\hline Mephitis mephitis & 2 & al & Wade-Smith \& Verts (1982) \\
\hline \multicolumn{4}{|l|}{ Mustelidae } \\
\hline Eira barbara & 1 & scansorial & Presley, 2000 \\
\hline \multicolumn{4}{|l|}{ Nandiniidae } \\
\hline Nandinia binotata & 1 & arboreal & Nowak (2005); Taylor (1976) \\
\hline \multicolumn{4}{|l|}{ Procyonidae } \\
\hline Procyon lotor & 3 & scansorial & Nowak (2005) \\
\hline Ursidae & & & \\
\hline
\end{tabular}




\begin{tabular}{|c|c|c|c|}
\hline Melursus ursinus & 1 & scansorial & Nowak (2005); Van Valkenburgh (1987) \\
\hline $\begin{array}{l}\text { Ursus americanus } \\
\text { Viverridae }\end{array}$ & 2 & scansorial & Nowak (2005) \\
\hline Arctictis binturong & 2 & arboreal & Nowak (2005) \\
\hline Paradoxurus sp. & 1 & arboreal & Nowak (2005) \\
\hline
\end{tabular}

1

Peer) reviewing PDF | (2019:10:42665:1:0:NEW 12 Jan 2020) 
Table 2 (on next page)

Three-dimensional landmark and curve definitions. 
Table 2. Three-dimensional landmark and curve definitions.

No

\begin{tabular}{|c|c|c|c|}
\hline . & Name & Definition & Type \\
\hline L1 & ASIS & $\begin{array}{l}\text { The anterior-most point on the lateral extent of the iliac crest (anterior superior iliac } \\
\text { spine); site of attachment for } m \text {. sartorius (Lewton, 2012, 2015a) }\end{array}$ & II \\
\hline L2 & Alls & $\begin{array}{l}\text { The anterior-most point on the anterior inferior iliac spine. If only a bony roughening, } \\
\text { the point in the center of the AllS rugosity; site of attachment for } m \text {. rectus femoris } \\
\text { (Lewton, 2012, 2015a) }\end{array}$ & II \\
\hline L3 & Lateral ilium & $\begin{array}{l}\text { The lateral-most point on the lateral aspect of the iliac margin, above the AllS, where } \\
\text { the cross-section of the lower ilium is smallest (Lewton, 2012, 2015a) }\end{array}$ & III \\
\hline L4 & PSIS & The superomedial-most point on the posterior iliac crest (Lewton, 2012, 2015a) & II \\
\hline L5 & Inferior auricular surface & $\begin{array}{l}\text { The inferior-most extent of the auricular surface, on the dorsal aspect of the pelvis } \\
\text { (Lewton, 2012, 2015a) }\end{array}$ & II \\
\hline L6 & Dorsal ilium & $\begin{array}{l}\text { The dorsal-most point on the dorsal aspect of the lower ilium, where the cross-section } \\
\text { of the lower ilium is smallest. Taken directly across from Landmark } 3 \text { (Lewton, 2012, } \\
\text { 2015a) }\end{array}$ & III \\
\hline L7 & Ischial spine & $\begin{array}{l}\text { The dorsal-most projection of the spine located on the posterior ischium, medial to the } \\
\text { acetabulum (Lewton, 2012, 2015a) }\end{array}$ & II \\
\hline L8 & Ischial tuberosity & $\begin{array}{l}\text { The dorsal-most point on the posterior ischium, medial to the acetabulum (Lewton, } \\
2012,2015 a \text { ) }\end{array}$ & II \\
\hline L9 & Superior acetabulum & $\begin{array}{l}\text { The point on the superior rim of the acetabulum that marks the intersection of the iliac } \\
\text { margin and acetabulum, which is defined as the extension of the line connecting ASIS } \\
\text { and AllS (Lewton, 2012, 2015a) }\end{array}$ & III \\
\hline $\begin{array}{c}\mathrm{L} 1 \\
0\end{array}$ & Inferior acetabulum & $\begin{array}{l}\text { The point on the inferior rim of the acetabulum directly across from Landmark 9, along } \\
\text { the long axis of the ischium (Lewton, 2012, 2015a) }\end{array}$ & III \\
\hline $\begin{array}{c}\mathrm{L} 1 \\
1\end{array}$ & Mid-acetabulum & $\begin{array}{l}\text { The center of the acetabulum; defined as the midpoint of the line between Landmarks } \\
9 \text { and } 10 \text { (Lewton, 2012, 2015a) }\end{array}$ & III \\
\hline $\begin{array}{l}\mathrm{L} 1 \\
2\end{array}$ & Ischium & $\begin{array}{l}\text { The distal-most point on the ischium that forms a line with the center of the } \\
\text { acetabulum that is parallel to the long axis of the ischium (Lewton, 2012, 2015a) }\end{array}$ & III \\
\hline $\begin{array}{l}\mathrm{L} 1 \\
3\end{array}$ & Superior pubic symphysis & $\begin{array}{l}\text { The superior-most point on the pubic symphysis, taken on the most medial point of the } \\
\text { pubis (Lewton, 2012, 2015a) }\end{array}$ & II \\
\hline $\begin{array}{l}\mathrm{L} 1 \\
4\end{array}$ & Inferior pubic symphysis & $\begin{array}{l}\text { The inferior-most point on the pubic symphysis, taken on the most medial point of the } \\
\text { pubis (Lewton, 2012, 2015a) }\end{array}$ & II \\
\hline
\end{tabular}


L1 Transverse diameter of

6 pelvis

L1 Medial ilium

L1

Iliac crest

C3 Dorsal ilioischial curve
The point that marks the intersection of the arcuate line of the ilium and the sacrum (Lewton, 2012, 2015a)

The point on the arcuate line that constitutes the maximum distance between the arcuate line of the opposing os coxa (Tague, 2005; Lewton, 2012, 2015a)

The medial-most point on the medial aspect of the lower ilium, where the cross-section of the ilium is the smallest. Taken directly across from Landmarks 3 and 6 (Tague, 2005; Lewton, 2012, 2015a)

Maximum projection of the pectineal tuberosity (Álvarez et al., 2013)

Cranial end of the major axis of the obturator foramen

Caudal end of the major axis of the obturator foramen

Cranial end of the minor axis of the obturator foramen

Caudal end of the minor axis of the obturator foramen

Ventral-most point on the cranial lunate horn

Ventral-most point on the caudal lunate horn

\section{Curve from points 1 to 4}

Curve from points 15 to 13

Curve from the piriformis tubercle cranially to point 8

Acetabular rim - external

Curve from points 23 to 24 , on the external aspect of the acetabular rim

Curve from points 23 to 24 , on the internal aspect of the acetabular rim

Curve from points 8 to 14 semilandmark

curve

semilandmark

curve

semilandmark

curve

semilandmark

curve

semilandmark

curve

semilandmark

curve 
C7

Lateral iliac margin

Curve from points 1 to 9

C8 Obturator foramen

L: landmark, C: curve semilandmark

curve

semilandmark curve 
Figure 1

Three-dimensional landmark positions.

Three-dimensional landmarks are shown in ventral (A), lateral (B), and dorsal (C) views on a fox (Vulpes Vulpes) os coxae. Landmark and curve definitions are listed in Table 2.

A

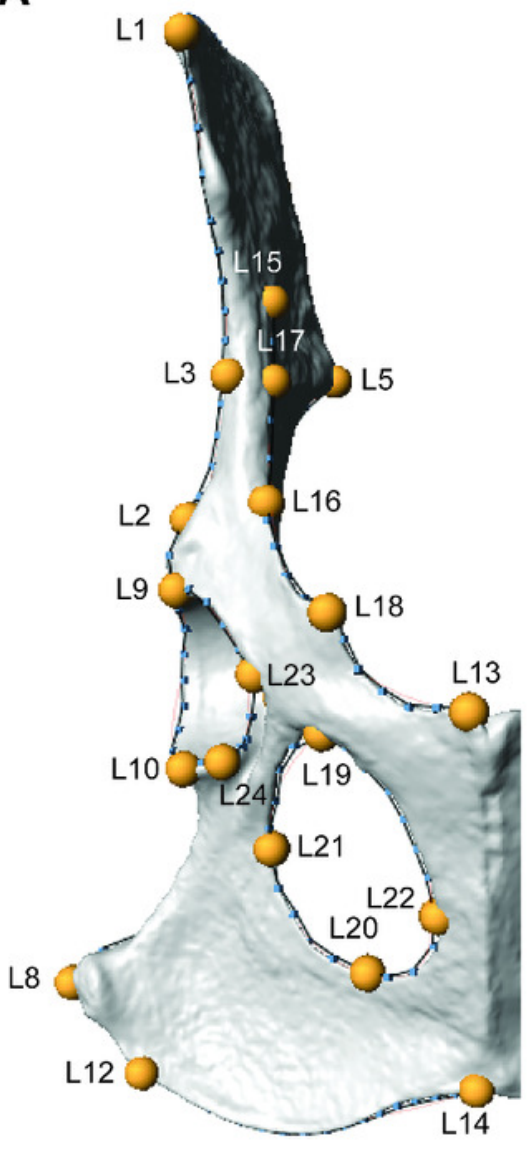

B

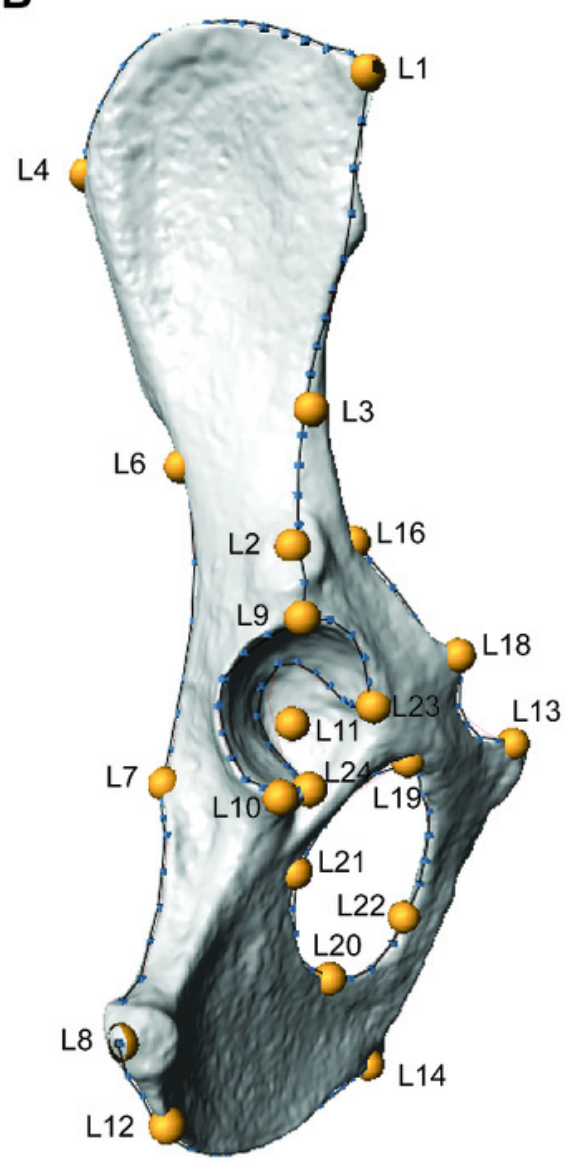

C

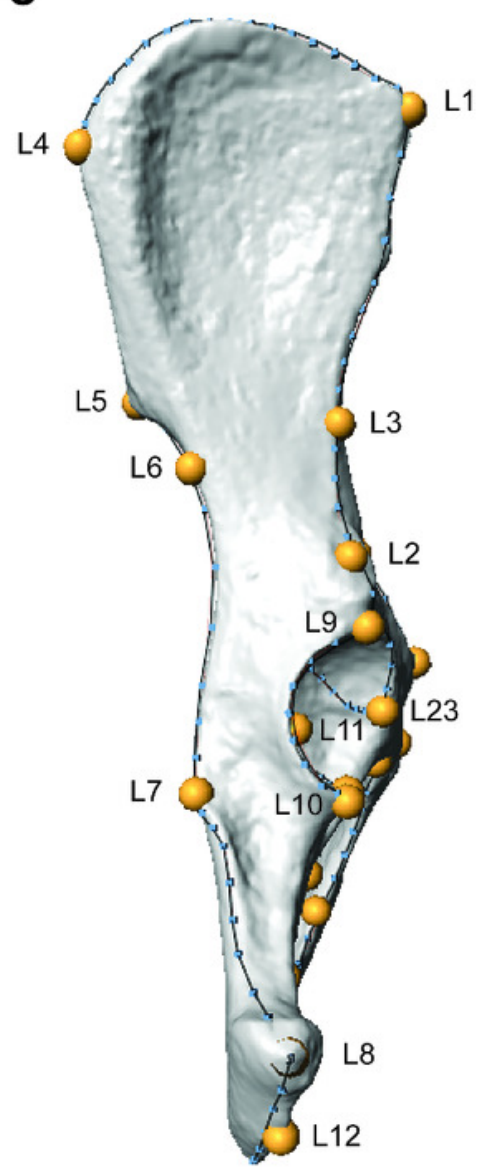


Figure 2

Phylomorphospace plots and representative os coxae shapes.

Phylomorphospace plots for PC1 on PC2 (A) and PC3 on PC4 (B). The phylogeny is shown in grey, points correspond to species means PC scores, colored by locomotor category. Legend in (B) follows (A). The os coxae shapes represented by the extremes of the PC axes are shown on the right. 
A

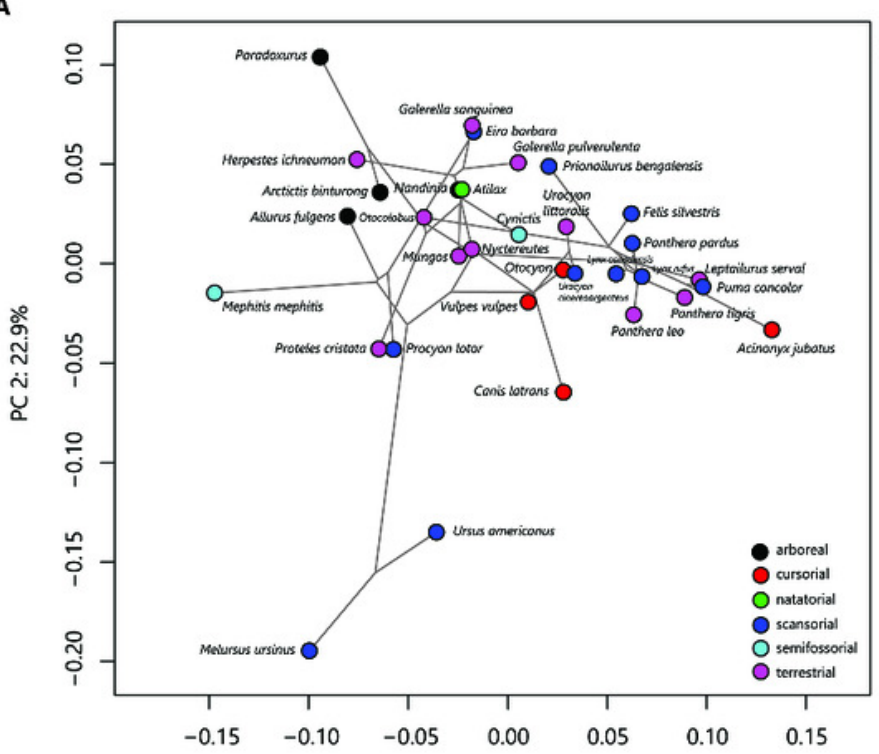

PC 1: $31.2 \%$

B

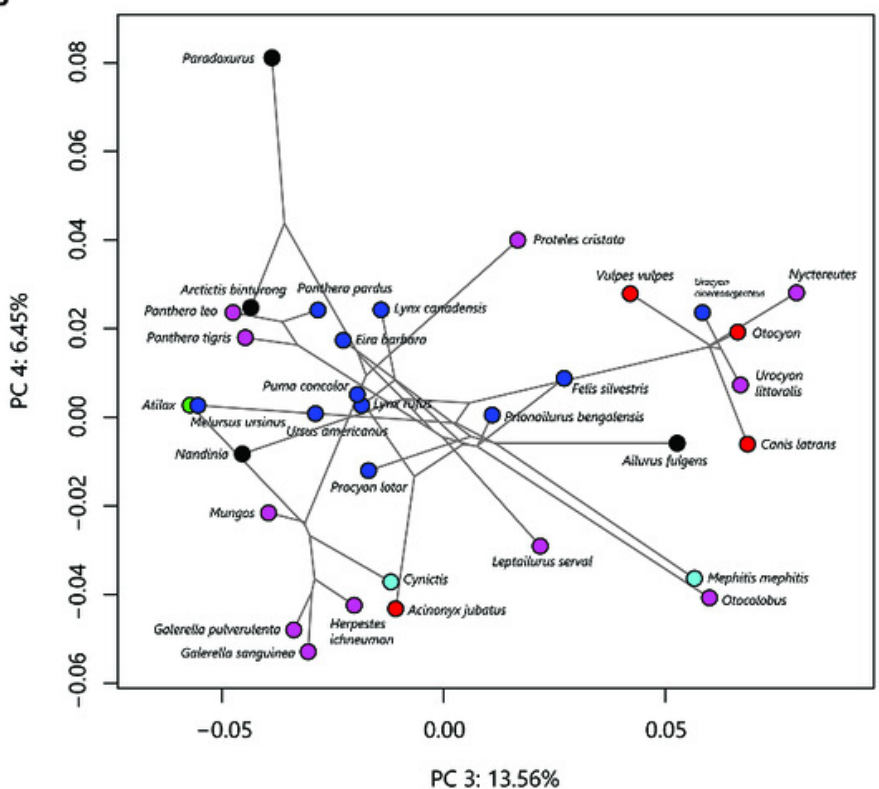

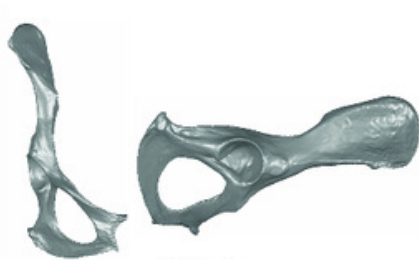

PC1 min

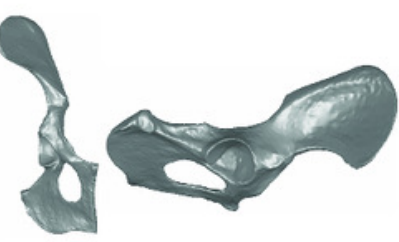

PC2 min

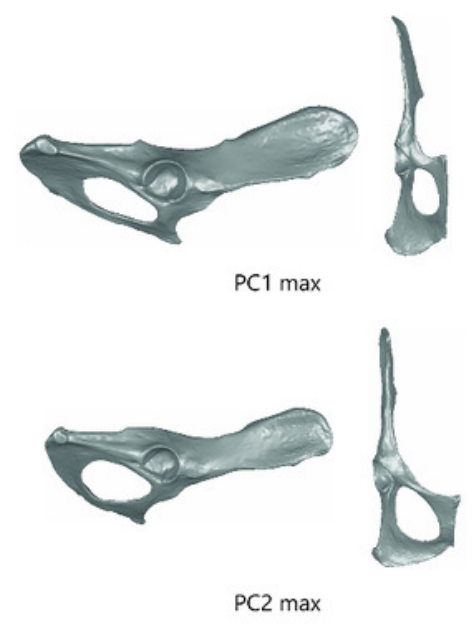

PC1 max

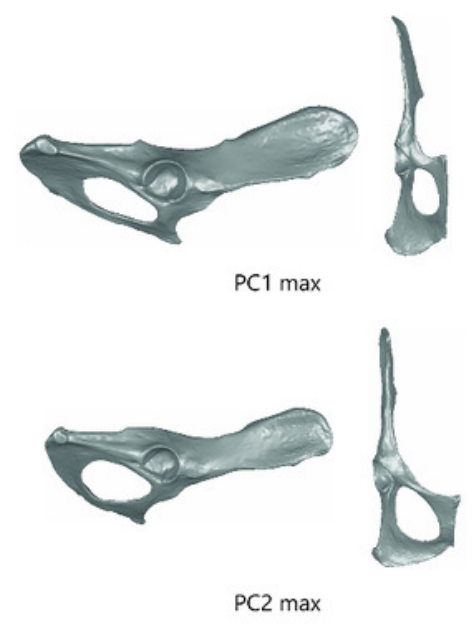

PC2 max

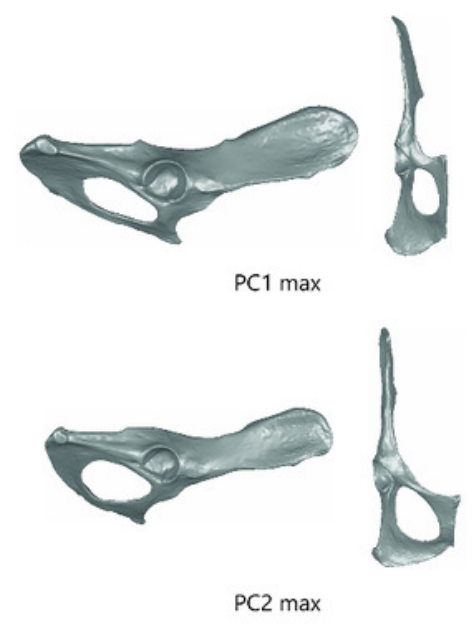

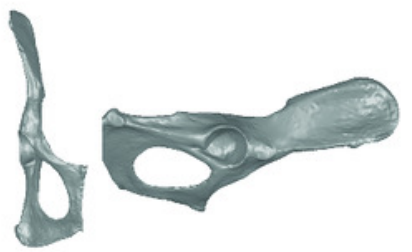

PC3 min

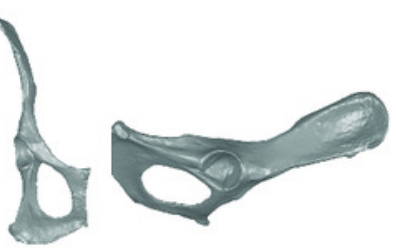

PC4 min

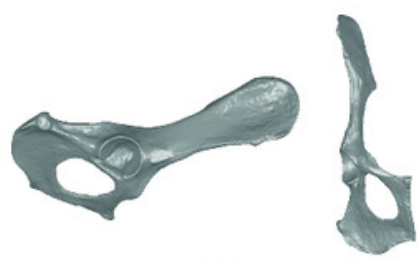

PC3 max

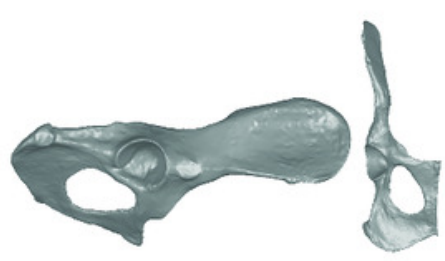

PC4 max 